\title{
Thinking and Practice Research on Art of Sketch Education- Using Heart to Sketch the Shape
}

\author{
Wenqing Wei \\ Jingdezhen Ceramic Institute, Jingdezhen, Jiangxi 333403, China
}

Keywords: Fine art; Sketch; Using "heart" to sketch the "shape"

\begin{abstract}
Art as a discipline, has attached more and more attention, sketch as the important one aspect, has been a lot of controversy in the teaching method, this paper puts forward some thinking points treating using "heart" to sketch the "shape" based on the current situation of sketch
\end{abstract} education.

With the increasing interest in art, art as a discipline in the major colleges and universities become increasingly hot up. The majority of institutions are hoping to start this piece of "art" brand. While sketch, is the basis of shaping arts, but also the basis of learning art. It is a skill that all the students who study art must master, but now they are faced with some difficulties, so, sketch and even art teaching reform have become an urgent problem to be solved.

Most of the current sketch education model still remain in the simply teaching techniques stage, purely depicting the image, so that the content is too "rigid", in other words, that works lack of tension and creativity. The reason for this situation is not enough skill, nor the lack of ability of teachers, or students learning it are not serious enough. I think its real crux is that we have not achieved the using "heart" to sketch the "shape".

The so-called using "heart" to sketch "shape", the first meaning is to use "heart" to feel the beauty of art. If you want to learn to feel beauty, first of all to learn "observation", "observation" does not mean "see", "observation" is active, and "see" is implied passive meaning; the core of "observation" is the process, "see" focusing on the results. In order to observe the images we have to describe, we must not only look at every detail of it, but also regard the heart as a pair of invisible hand, to touch its "soul", feel its inner vitality, and even find a breakthrough, pouring your emotions. For example, when we face a building, not only to show its shape and its material, but also to show its unique historical and cultural heritage, regional characteristics, etc. At this point, we can through their own feelings create a special or even exaggerated changes in light and shade, the surrounding environment set off or other ways to express the things we feel. Second, specifically training this ability, we should establish a model of the combination of that short-term task and long-term task, short-term task is based on the current arrangement of the task, long-term task is to gradually master more skills, at the same time, make continuous changes on the works in the process, in the process of completing long-term tasks, students through self-examination can consolidate and master a variety of skills. This teaching process should be "from shallow to deep, from the surface to inner, from simple to complex, step by step", students only through the heart to experience their own works have more and better ideas to improve, so that works better express their own will, to give their work vitality. (1)

In fact, if you want to be felt carefully, difficult or not difficult, just a little, that is the love of art. In the present education system, less and less students learning art is really loving art. Only in a love of art heart, I think all of the above will not be so difficult. It is difficult to train students how to cultivate the love of art. As a teacher, we should be appropriate to change our teaching methods, the most important point is to stimulate students to the initiative of learning, so that students are in the main position, they participate in the creation of the discussion, appropriately guided by the teacher, rather than blindly instill their own ideas, after all, everyone has their own unique preferences, a teacher's ideas and opinions do not necessarily apply to each student. If you only use their own ideas to unify the standard of appreciation works, will stifle students' independent interest and ability, especially for college students, at their stage, the need to fully explore their sense of innovation. In addition, we should try to use their passion for art, using the enthusiasm of the 
teaching to infect and drive students to create a relaxed and lively classroom atmosphere, in this case, students are willing to learn, and play out creative activity to a great extent, so as to cultivate their enthusiasm for the sketch and even art. Moreover, we should be with the appreciation of the attitude of students, to be good at discovering their thinking of the flash point, and promptly encouraged to encourage them to find the fun of learning art, for the evaluation of academic performance, we need to do it with the appropriate nature of encouragement, such as narrowing points difference with the excellent and the average student, so that all students feel that they are promising, naturally there is confidence. In the confidence of the encouragement, they will be able to complete more valuable works. (2)

If we want to use "heart" to sketch "shape", naturally we need to have a certain grasp of "shape". It is necessary to mention that the "shape" we have traced must come from reality. It sounds like funny: the image we describe must be from reality ah! However, the "reality" that I am saying here refers not only to the fact that the things exists in reality, but if just so, all works of art can be replaced directly by "photograph", so that there is no meaning of sketch and arts. So, in my opinion, we should encourage students to be more close to life, integrate into life, to find true and beautiful moments. At present, our sketch education has the so-called "sketch" class, but in my opinion, is not enough, our sketch theme, should not just characters, scenery, architecture and other common themes, but should all the things that appear in life. Or even some of the moment the students can capture, it can be said that the sketch of the subject matter should exist in the student's life at all times. However, our creation should not be camera-like, that is, the whole life will be the original image of the original copy into the work, but should be "shape" of art processing. Only in the prototype of the successful re-creation, it can be called a good work. Such as Van Gogh's "Star", even if you are not told what the name of this piece of work, presumably you can guess he painted is the "Star", but the sky we see is exactly that? The answer is clearly negative, it is obvious that in this piece of work, we feel the artist's boundless imagination. It is also because of his kind of "reality" in the "imagination", only to make this painting fame. Therefore, the creation of students also need to base on reality, to play out its creativity, of course, we can't make any imagination fly free, or its works can not be called "sketch". Another point "Shape", that is, "modeling", we should think, in what "modeling", the works can attract the eye? We all know that for a sketch works, the most bright spot is often the shape. While now the shape of the work of the students are often monotonous, some students reflect to me, when they read so many masterpiece after the admiration, naturally tend to imitate, especially imitation of the famous painting. The results are they lose themselves, not only the charm disappear, and even their understanding of the work is gone. As a result, the value of the works become general, so should we not follow the famous works? Obviously not, we want to let the students understand that the imitation to the famous masterpiece is not "plagiarism", to imitate the technique and thinking method, is the process of how the famous master break the work. Therefore, in the process of imitating the famous, we must remind the students to maintain a "modeling" consciousness, that is, our students need a pair of "find beauty" eyes and a "create beauty", forget the so-called "rules of the rules", so that "my hand" paint "my heart".

In summary, using "heart" to sketch the "shape" requires that students must be driven by the enthusiasm of the sketch, take the initiative to observe life, find the subject within the scope of all possible realities, carefully explore the breakthrough of subject, through their own creative creativity, to show the vitality of the image and its inherent quality. In this way, sketches, this kind way of expression can be enduring, fine arts can maintain the vitality forever.

\section{Acknowledgements}

Fund Project: This article is one of the phased results of the "Reform and Exploration of Photoshop Teaching in the UI Interface Design" Project of the Young Teachers' Teaching Reform Research Fund of Jingdezhen Ceramic University in 2016. 


\section{References}

[1] $\mathrm{Wu}$ Yun. "Thinking on the teaching of sketches in the teaching". Journal of Nanchang College of Education, 2011

[2] Yang Yao. "Cultivate interest of art to create creative thinking - Research on the effectiveness of art teaching", 2011 